\title{
The Effects of E-Learning on Students' Motivation to Learn in Higher Education
}

\author{
Elgilani Elshareif \\ Canadian University Dubai \\ Elfadil A. Mohamed \\ Ajman University
}

\begin{abstract}
The recent COVID-19 pandemic has forced educational institutions worldwide to adopt e-learning. UAE higher education institutions have implemented e-learning systems and programs to cope with this unprecedented situation. This paper measured the strength of association between key aspects of e-learning systems and programs and students' motivation to learn in Ajman University (AU). Cronbach's coefficient alpha was used to test the internal consistency reliability of key aspects of e-learning (EL-8) and students' motivation to learn (SML-16). Exploratory factor analysis was used to test the validity of, and coherence of patterns in, the data. Parametric and nonparametric methods were used to investigate the strength of association between key aspects of elearning and students' motivation to learn in AU. The results indicated that motivation variables were more strongly correlated with both e-teaching materials and e-assessments key aspects relative to others such as e-discussion, and e-grade checking and feedback.
\end{abstract}

Keywords: internal consistency, key aspects of e-learning, motivation to learn, factor analysis

Elshareif, E. \& Mohamed, E. (2021). The effects of e-learning on students' motivation to learn in higher education. Online Learning, 25(3), 128-143. doi:10.24059/olj.v25i3.2336 
E-learning becomes an important means of knowledge and skill acquisition in higher education institutions. Students' motivation to learn contributes to knowledge acquisition and hence is of paramount importance to their success in the future. Many factors impact students' motivation to learn, and the question of how to stimulate student to learn remains the subject of much research. As concerns teachers, their role in the educational process is to create a positive environment which encourages learning and students' long-term success (Vero \& Puka, 2017). Moreover, it is suggested that for students to increase their academic knowledge, they must be active in processing such knowledge. Chan et al. (2015) examined the impact of students' perceived autonomy support (explained as student perception of support received from their teacher in promoting self-learning) on learning motivation using in-lecture and after-lecture learning through the mediation of social-cognitive (defined as psychological processes that allow students to take benefits of social interaction) factors. The results indicate that perceived autonomy support plays an important role in promoting self-learning and motivation in the three samples from the U.K., China, and Pakistan.

Another factor with an immense impact on augmenting student knowledge is the use of a course learning management system. Different course management systems (CMS) have been developed and used by higher education institutions. One very popular CMS used by many higher education institutions as a complement to face-to-face learning is Moodle (Rice, 2015). These elearning systems and programs have played an important role in improving the interaction between students and teachers.

This research focuses on four key aspects of Moodle activities, which are referred to as key aspects of e-learning: (1) e-teaching materials, (2) e-discussions, (3) e-assessments, and (4) e-grade checking and feedback.

The key aspects of e-learning inspired by the Attention Relevance Confidence Satisfaction (ARCS) model provide many meaningful benefits to the learning experience. First, they offer faculty a variety of powerful tools such as real-life case studies, short videos, social media, and invitations to guest speakers, etc. to enhance students' motivation to learn. Secondly, the tools are integrated with fun and intrinsic rewards to improve students' desire to access, attend, and actively participate in the e-learning course and cultivate the rewards of their contributions to course learning outcomes. Finally, the integration of key aspects of e-learning with ARCS model may help faculty to critically think about and accommodate students' interests and desire to learn and engage them emotionally.

Given the importance of the intensive use of information and communication technology (ICT) and its constructive impacts on the e-learning experience in higher education (Wan, Wang, \& Haggerty, 2008), this study examined the use of Moodle in supporting e-learning resources in higher education. Prior research has suggested different key aspects of e-learning, such as emoderating, e-design, e-communication, workload, and interactivity (Prosser \& Trigwell, 1999). However, it is notable that the literature offers limited evidence on ARCS and key aspects of elearning related to the use of Moodle in higher education. Hence, this study attempts to fill this gap by identifying four underlying key aspects of e-learning within Moodle. 


\section{Research on Online Learning}

\section{Literature Review}

E-learning systems and programs have played an important role in improving the interaction between students and teachers. Among the prominent activities provided by learning management systems are e-teaching materials, which can be presented in different formats. Eteaching materials in the form of open educational resource (OER) textbooks are discussed by Dennen and Bagdy (2019). Their study indicated that students have given positive feedback on OER textbooks and that this type of material contributed to helping them meet course learning objectives. One recent study found that course activities aligned with learning objectives such as case studies, group assignments, problem solving, and peer-to-peer interaction have the highest impact on both student learning and engagement (Sadaf et al., 2019).

E-discussion that aims to engage students with their instructors, course content, or with each other via synchronous or asynchronous modes has been well documented in the literature. A study conducted by Truhlar et al. (2018) examined the effects of synchronous chats in an online course and found that assigning roles to students increased the proportion of studentstudent interaction. Prior research has also revealed that online discussion and engaging in interactive assignments stimulate students to share their opinions and develop a personal perspective (Buelow et al., 2018). Student opinion of the use of online discussion forums varies across discussion types: structured discussion forums (guided discussion with clearly identified topic) were received more positively by students than unstructured (students select the topic on mutual basis) ones (Tibi, 2018).

Asynchronous discussion in an online environment is also investigated by Mitchell (2019). The majority of students in that study indicated that the debate assignment assisted them in comprehending the course concepts and understanding them better.

\section{Research on Online Learning, ARCS, and Motivation}

Learning generally is the interaction between several components, including students, teachers, methods, technology, teaching materials, and assessment tools. Universities have examined a wide range of means to make a direct or indirect impact on improving the quality of the learning they offer, including students' knowledge, skills, and level of competency (Tokan \& Imakulata, 2019). In particular, the role and value of e-learning in boosting motivation to learn has been a topic of considerable recent study. Universities have recognized student motivation to learn as an integral means of knowledge acquisition and many studies have been carried out aiming to find the relationship between effects of e-learning and on student motivation to learn.

The prominent ARCS model which is composed of four components-Attention, Relevance, Confidence, and Satisfaction - is used to inspire students' motivation to learn (Keller, 1987a). The attention component captures the interest of students and the curiosity necessary to learn. The relevance component captures the general goals of the students to inculcate good learning behaviors. The confidence component attempts to help students improve their confidence that they will succeed and are in control of their own success. The satisfaction component tries to reinforce accomplishment by means of both internal and external rewards.

Harandi (2015) investigated the strength of the relationship between e-learning and motivation among a sample of students and concluded that students' motivation is broadly impacted by e-learning. Other studies have considered the different ways in which e-learning can be delivered and assessed the role of each component in boosting motivation. Maulana et al. (2019) proposed using the three-pillar approach; social media, technology, and society (STS) to increase enthusiasm for independent learning, with results indicating that such an approach can 
improve self-learning motivation. Another medium that can be used to improve students' motivation to learn is via technology, which has been proved to leverage vocational students' motivation to learn (Irawan et al., 2019). Recent developments in ICT, such as mobile phones, can also motivate students to learn. Imansari et al. (2018) indicated that e-books as a learning medium can improve such motivation in the case of studying history.

Paechter and Maier (2010) cited one of the studies addressing which aspects of e-learning courses students prefer and found that e-teaching materials are an important aspect of e-learning and contribute to motivating students to learn. E-teaching materials constitute the interface between students and an e-learning system and therefore the role of such materials in fostering motivation to learn also merits assessment. Yili and Tsai (2017) have analyzed e-learning teaching materials used by computer science students undertaking a mobile phone programming course. They found that students regarded the e-learning system teaching materials as far better than paper-based ones. These e-teaching materials contributed to students' performance and motivation to learn. In the same direction, Slater and Davies (2020) indicated that students prefer lectures, course notes, and primary literature available online, because these e-teaching materials were perceived as available and easy to engage with from outside the university campus. A study by Cundell and Sheepy (2018) found that e-teaching materials available online were highly rated by students in terms of importance in blended learning.

Asynchronous discussion, a form of e-discussion as a means of motivating students to learn, also merits study. Chan et al. (2016) explored the importance of asynchronous discussion in relation to students' self-preferences, level of engagement, and motivation. Their findings indicated that students' preferences, commitment, and participation in asynchronous discussion indirectly led to improvements in their motivation to learn.

Karagiannis and Satratzemi (2018) proposed a flexible technique in Moodle, which builds to capture both learner attitude and knowledge. Their proposed approach is based on a hybrid dynamic user model that was developed with technique based on learner knowledge and behavior. The experimental results indicated their approach affected students' motivation and performance. Researchers are engaged in ongoing study of the relationship between motivation to learn using e-learning systems and face-to-face learning. Zheng et al. (2018) assessed online self-regulated environments and learners' motivation using a structural model. Their results revealed that learners who have a motivated online learning experience tend to be more independent in the learning process and experience. Recent research (Stark, 2019) found that although the online students indicated a low level of motivation in contrast to face-to-face students, motivation variables were more strongly correlated with the course performance than learning strategies for online courses. A study of online learning conducted by Pugh (2019) revealed an association between gender and motivation, but no correlation between age and motivation.

Many psychologists and researchers have considered that students' motivation to learn is among the factors that most contribute to both face-to-face and online learning experience and academic success (Keller, 1987a; Snow, 1990; Tseng \& Walsh, 2016; Kim et al., 2017). Keller (1987a, 1987b, 2008) proposed, designed, and offered the ARCS model discussed above, identifying the four basic components (i.e., Attention, Relevance, Confidence, and Satisfaction) used to stimulate students' motivation to learn. The proposed model assumes that students can be more viably and reliably motivated to learn if the motivational dynamics associated with these four factors are taken into consideration. Each component has its own motivational concern. First, attention means that students' attention to given instructions is attracted and retained. 
Second, relevance requires the instructions to be connected to students' personal missions and goals. Third, a suitable level of confidence and positive expectation must be created as regards the learning process. Finally, satisfaction entails developing students' attitudes to ensure a continuing desire to participate in the learning process, with clear goals.

The ARCS model helps course designers in creating a learning experience that capture students' interest. Therefore, the ARCS model helps instructors to make specific changes in each course using ARCS components to stimulate students' motivation. Following Keller (1987b), instructors can use the four components with the objective to capture students' interest, address their needs, enhance their confidence for success, and provide them with meaningful opportunities. First, in reference to attention, instructors can present teaching materials in different formats, post challenging questions, and use real case studies. For the relevance component, instructors need to understand the students' background and experience and establish relevance via group peer-to-peer discussion or initiating in class series of guest speakers. To equip students with confidence, instructors need to establish a framework that guide students from fundamental knowledge to more specialized one that help them achieve challenging learning outcomes via giving students challenging and unfamiliar assignments. Finally, instructors must ensure that appropriate opportunities have been given to students to demonstrate their achievement of the course learning outcomes in ways other than course grading and assure that feedbacks and rewards are meaningful to them.

Chang and Lehman (2002) embedded relevance, one of the components of ARCS model, in computer-based interactive multimedia (CBIM) program used for teaching English as a foreign language to students. One of the findings of their study indicated that the performance of the students who learned from a CBIM program with an embedded relevance motivational strategy was better than students who learned from a CBIM program without an embedded relevance motivational strategy.

Prior literature showed that the ARCS model has become an integral part of academic learning activities. Hirumi et al. (2012) employed ARCS to assess two online courses, with their findings suggesting that learners' perceived levels of motivation were higher for the two online courses in which the ARCS model was used than in the conventional courses. Students' motivation to learn is considered one of the key drivers for an effective learning system in higher education (Kim et al., 2017; Guo et al., 2017). Recently, a flipped classroom design using the ARCS model to improve students' engagement and passion for learning is applied by (Songül \& Polat, 2019). Findings revealed that the students' academic performance using the flipped classroom with the ARCS model was far better than in the distance education classroom model and the traditional classroom model.

The aim of this research was to measure the association between key aspects of elearning systems and students' motivation to learn in online courses. Therefore, the following two research questions guided this research:

1. Which are the key aspects to consider in order to motivate students to learn in an elearning environment using motivation factors within the ARCS model?

2. Is there any association between aspects of e-learning and students' motivation to learn? 


\section{Methods}

To answer the research questions, the study identified the ARCS as a key reason for learning and integrated this model with the four key aspects of e-learning, namely e-teaching materials, e-discussions, e-assessments, and e-grade checking and feedback.

\section{Setting}

Ajman University (AU) was established in 1988 in the Emirate of Ajman in UAE. The QS World University Rankings (QSWUR) 2021 edition lists AU among the top 750 institutions globally by ranking it in the 701-750 band. In 2006, AU introduced Moodle as a course management system that aims to complement the face-to-face learning system. Moodle provides useful activities that help both students and educators in accomplishing a variety of tasks. The first two colleges that started implementing Moodle are College of Business Administration (CBA) and the College of Engineering and Information Technology (CEIT). All instructors are required to use varieties of Moodle activities such as uploading teaching materials, assignments, quizzes, forums, etc.

\section{Sample}

The sample was recruited from students registered in two colleges: CBA and CEIT at Ajman University. Several types of purposeful sampling strategies are used in prior research, of which criterion sampling is the most used in applied study (Palinkas et al., 2015) and has been adopted in the present study. The first criterion used for the selection of the students was based on their prior experience of using Moodle. All faculty members at the two colleges currently use Moodle as their CMS. Based on this criterion, the target participants of 160 students came from the CBA and CEIT colleges. Of the 160 students, 108 responded and completed the questionnaire, representing $68 \%$ of the target participants. The second criterion aimed at heterogeneity of study level. Only students who had finished at least one year and dealt with more than two courses that involved the use of Moodle were selected.

The selected students completed the survey form at the end of the class. In the first part of the survey, the participants provided the demographic data whose characteristics are shown in Table 1.

Table 1

Demographic Analysis of Data Sample

\begin{tabular}{cccc} 
& Variables & Frequency & Percentage (\%) \\
\cline { 2 - 4 } Gender & Male & 50 & 46 \\
& Female & 58 & 54 \\
Age & 18 and under & 2 & 1.9 \\
& $19-21$ & 52 & 48.1 \\
& $22-24$ & 41 & 38.0 \\
Total & Over 24 & 13 & 12.0 \\
\hline
\end{tabular}

\section{Likert Scales Included in the Survey}

The Likert scales and questions employed in this work are based on earlier research (Rahrouh et al., 2018; Keller, 1987a; Paechter \& Maier, 2010). Additionally, to finalize the set of scales and questions a pilot was conducted with a small focus group of colleagues in the field. Respondents were asked to provide their opinion on 24 statements using a five-point Likert scale 
( 1 = "strongly disagree" and $5=$ "strongly agree"). These statements are related to the most-used Moodle activities (EL-8) and the ARCS motivation model (SML-16). These 24 questions were divided into two subscales to maximize the outcome of the research and let the data patterns reveal new insights. The first subscale is related to e-learning key aspects and consists of eight questions defined as EL-8. The second subscale is about motivation and consists of 16 questions defined as SML-16.

The key aspects of e-learning (EL-8) are presented in Table 3. These key aspects are eteaching materials (items 1 and 2), e-assessments (items 3 and 4), e-discussions (items 5 and 6), and e-grading and feedback (items 7 and 8). On the other hand, the items related to students' motivation to learn (SML-16) are shown in Table 4, soon after the reliability analysis.

\section{Reliability of Instrument}

The reliability of the research instrument was measured using Cronbach's alpha (Cronbach, 1951). Cortina (1993) stated that the alpha should be estimated for each dimension of a scale rather than for the entire scale. Following this argument, Table 2 presents the internal consistency reliability of both key aspects of e-learning-8 (EL-8) and student motivation to learn (SML-16). According to the coefficient alpha, the internal consistency reliability of EL-8 and SML-16 is 0.944 and 0.973 , respectively. The value of Cronbach's alpha suggested that the items of the EL-8 and SML-16 were reliable.

Table 2

Summary Statistics and Cronbach's Alpha for EL-8 and SML-16

\begin{tabular}{lll}
\hline Variables/Statistics & EL-8 & SML-16 \\
\hline Cronbach's alpha & 0.944 & 0.973 \\
Mean & 3.77 & 3.62 \\
Std. Deviation & 0.894 & 0.911 \\
Std. Error Mean & 0.086 & 0.087 \\
Skewness & -0.889 & -0.665 \\
Kurtosis & 1.602 & 0.856
\end{tabular}

Table 2 also reports the descriptive statistics for both EL-8 and SML-16. Two important observations can be made from the summary statistics. First, the indices had a positive mean of 3.77 and 3.62, respectively. Second, the two indices are negatively skewed, and kurtosis is below the standard of 3 , implying that the two variables behave linearly.

\section{Data Analysis}

To analyze the quantitative research data, IBM SPSS Version 26 was used. To assess the presence of latent factors emerging from students' answers to the Likert-scales, exploratory factor analysis (Hoban et al., 2005) was performed. Next, the parametric (Pearson $r$ ) and nonparametric (Spearman rank) correlation methods were employed to address research question 2, namely the assessment of the degree of association between factors.

The rationale for using the two methods is twofold. First, key aspects of e-learning and students' motivation to learn are assumed to behave linearly (parametric method); however, if variables tend to behave in a monotonic way, then it would be better to use a non-parametric method. Secondly, the parametric method is often used to assess relationships concerning an interval scale while a non-parametric method is used for ordinal variables (Lim \& Park, 2011). 
The parametric method is more informative than the non-parametric one in the sense that it uses information about the mean and deviation from the mean while the non-parametric method only uses the ordinal scale or spectrum of values.

\section{Survey Findings and Results from Analyses}

Table 3 and Table 4 summarize student responses using mean scores and Likert scale response percentages for key aspects of e-learning and students' motivation to learn, respectively. To address the first research question the five-point Likert scale was presented in three groupings as percentages: disagree, neutral, and agree (Ellis et al., 2009). Many conclusions can be drawn from these two tables. As documented in Table 3 and Table 4, certain issues are observed in this study and must be addressed.

Table 3

Key Aspects of E-Learning, 8 Items

Likert Scale Response: Mean and \% (Disagree, Neutral, Agree)

\begin{tabular}{llcccc}
\hline Item/Question\# & \multicolumn{1}{c}{ Mean } & Disagree & Neutral & Agree \\
\hline 1 & $\begin{array}{l}\text { My teacher uploaded course e-teaching } \\
\text { material and updated it on a regular } \\
\text { basis. }\end{array}$ & 4.01 & 7.4 & 14.8 & 77.8 \\
\hline $\begin{array}{l}\text { E-assessment tools, such as } \\
\text { assignments/projects/exams, were } \\
\text { uploaded by my teacher. }\end{array}$ & 3.93 & 9.4 & 16.8 & 73.8 \\
\hline $\begin{array}{l}\text { E-assessment tools, such as } \\
\text { assignments/projects/exams, are well } \\
\text { prepared, explained, and understood } \\
\text { by the students. }\end{array}$ & 3.92 & 7.4 & 24.3 & 68.2 \\
\hline 7 & $\begin{array}{l}\text { E-grade checking helps me to monitor } \\
\text { my performance. }\end{array}$ & 3.74 & 13 & 22.4 & 64.5 \\
\hline $\begin{array}{l}\text { Supplementary e-teaching material } \\
\text { such as further reading, exercises, } \\
\text { journal articles, etc. are uploaded. }\end{array}$ & 3.73 & 12.2 & 23.4 & 64.5 \\
\hline $\begin{array}{l}\text { During the course period, my teacher } \\
\text { discusses the importance of e- } \\
\text { discussions for understanding the face- } \\
\text { to-face learning experience. }\end{array}$ & 3.64 & 14 & 29.0 & 57 \\
\hline $\begin{array}{l}\text { E-discussions help me in } \\
\text { understanding challenging topics with } \\
\text { which I am not familiar. }\end{array}$ & 3.59 & 14 & 30.8 & 55.1 \\
\hline $\begin{array}{l}\text { E-grade checking improves } \\
\text { communications between my teacher } \\
\text { and me. }\end{array}$ & 3.56 & 14.9 & 31.5 & 53.7 \\
\hline
\end{tabular}


Table 4

SML Items

Likert Scale Response: Mean and \% (Disagree, Neutral, Agree)

\begin{tabular}{|c|c|c|c|c|c|}
\hline Item & & Mean & Disagree & Neutral & Agree \\
\hline 24 & $\begin{array}{l}\text { The e-grade checking assisted me in achieving } \\
\text { positive feelings about my success. }\end{array}$ & 3.80 & 10.4 & 21.7 & 67.9 \\
\hline 13 & $\begin{array}{l}\text { E-assessment activity such as } \\
\text { assignments/projects/exams captured my } \\
\text { interest and enhanced my learning experience. }\end{array}$ & 3.74 & 8.4 & 30.6 & 61.2 \\
\hline 22 & $\begin{array}{l}\text { The e-grade checking improved my feeling } \\
\text { about responsibility for success. }\end{array}$ & 3.73 & 9.5 & 31.1 & 59.4 \\
\hline 21 & $\begin{array}{l}\text { The e-grade checking captured my interest and } \\
\text { stimulated me to adopt an inquiring attitude. }\end{array}$ & 3.69 & 11.3 & 28.3 & 60.4 \\
\hline 20 & $\begin{array}{l}\text { The e-discussions provided me with a sense of } \\
\text { satisfaction with the process of learning } \\
\text { experience. }\end{array}$ & 3.66 & 11.3 & 30.2 & 58.5 \\
\hline 23 & $\begin{array}{l}\text { The e-grade checking provided me with } \\
\text { corrective feedback and allowed me to learn } \\
\text { from my mistakes. }\end{array}$ & 3.65 & 8.5 & 23.6 & 62.2 \\
\hline 14 & $\begin{array}{l}\text { E-assessment activity such as } \\
\text { assignments/projects/exams helped me in } \\
\text { meeting my personal needs. }\end{array}$ & 3.65 & 3.7 & 30.6 & 59.2 \\
\hline 15 & $\begin{array}{l}\text { E-assessment activity such as } \\
\text { assignments/projects/exams helped me to } \\
\text { believe that I would succeed and control my } \\
\text { success. }\end{array}$ & 3.63 & 6.5 & 29.6 & 57.4 \\
\hline 19 & $\begin{array}{l}\text { The e-discussions helped me in building a } \\
\text { positive expectation of success. }\end{array}$ & 3.63 & 7.4 & 32.4 & 55.6 \\
\hline 9 & $\begin{array}{l}\text { Interacting with e-teaching materials helped } \\
\text { stimulate my curiosity to learn. }\end{array}$ & 3.62 & 8.3 & 31.5 & 55.6 \\
\hline 18 & $\begin{array}{l}\text { The e-discussions assisted in stimulating my } \\
\text { personal engagement in the class. }\end{array}$ & 3.57 & 7.4 & 31.5 & 55.6 \\
\hline 16 & $\begin{array}{l}\text { E-assessment activity such as } \\
\text { assignments/projects/exams helped me to } \\
\text { acquire new knowledge and skills to solve real- } \\
\text { world problems. }\end{array}$ & 3.56 & 5.6 & 30.6 & 55.5 \\
\hline 11 & $\begin{array}{l}\text { Interacting with e-teaching materials increased } \\
\text { my confidence and motivated me to learn. }\end{array}$ & 3.53 & 7.4 & 32.4 & 53.7 \\
\hline 10 & $\begin{array}{l}\text { Interacting with e-teaching materials helped me } \\
\text { in meeting my personal goals. }\end{array}$ & 3.51 & 13.0 & 28.7 & 52.8 \\
\hline 12 & $\begin{array}{l}\text { Interacting with e-teaching materials resulted } \\
\text { in increasing my satisfaction and motivated me } \\
\text { to learn. }\end{array}$ & 3.51 & 12.0 & 31.5 & 50.9 \\
\hline 17 & $\begin{array}{l}\text { The e-discussions contributed to sustaining my } \\
\text { attention during my learning experience. }\end{array}$ & 3.50 & 7.4 & 36.1 & 49 \\
\hline
\end{tabular}


First, using the mean score, e-teaching and supplementary materials are perceived as being among the top priorities, scoring 4.01 and 3.73, respectively. In terms of the Likert scale related to e-learning key aspects, a majority of the students pointed to the importance of eteaching and supplementary materials, with percentages of 74.8 and 64.5 , respectively. This result coincides with that discussed in Paechter and Maier (2010) and Yili and Tsai (2017), who indicate that students prefer e-learning delivered in the form of PowerPoint lecture slides, videos, assignments, and chat box and forum messages with a clear goal.

Second, the mean score of the students' response to the e-assessments item suggested that the item is of high importance for their learning experience. Using a Likert scale, the majority of students indicated that e-assessments were important, with a value above $73 \%$ in relation to the key aspects of learning. Moreover, using a Likert scale, responses to item 13, 14, 15, and 16 suggested that most of the students pointed out that ARCS components were helpful with scores of 61.2 for attention, 59.2 for satisfaction, 57.4 for confidence, and 55.5 for relevance.

Finally, e-discussion and e-grade checking and feedback do not contribute to sustaining student motivation and represent a challenge in terms of improving communication between faculty and students. This result clearly emphasizes the importance of e-learning systems as a complementary teaching tool that can improve students' motivation to learn.

\section{Factor Analysis}

Exploratory factor analysis (Hoban et al., 2005) was used to assess the presence of factors. The analysis revealed three coherent factors; Factor 1: Teaching materials and assessments, Factor 2: Discussion, feedback, and intrinsic motivation, Factor 3: Extrinsic motivation. These factors were shown in Table 5 below. The three factors explained $69 \%$ of the variance with Eigenvalues of 18.03, 1.26, and 1.13, respectively. The eigenvalues of these three factors here are greater than one while all other factors evaluated in the principal component analysis (PCA) being a very small fraction indicate that along these three factors there is a lot of information as indicated in the Table 5 below.

Table 5

Factors and Standardized Loadings associate to the EL-8 and SML-16

\begin{tabular}{cc}
\hline \multicolumn{1}{c}{ Factors } & Factor Loadings \\
\hline Factor 1: Teaching materials and assessments & \\
Q1 & 0.769 \\
Q2 & 0.623 \\
Q3 & 0.719 \\
Factor 2: Discussion, feedback, and intrinsic motivation & \\
Q5 & 0.753 \\
Q6 & 0.816 \\
Q7 & 0.68 \\
Q8 & 0.595 \\
Q10 & 0.602 \\
Q11 & 0.678 \\
Q12 & 0.688 \\
Q13 & 0.625 \\
Q17 & 0.626 \\
Q18 & 0.728
\end{tabular}




$\begin{array}{ccc} & \text { Q19 } & 0.745 \\ & \text { Q20 } & 0.685 \\ & \text { Q21 } & 0.561 \\ & \text { Q22 } & 0.567 \\ & \text { Q23 } & 0.565 \\ & \text { Q24 } & 0.712 \\ \text { Factor 3: Extrinsic motivation } & & \\ & \text { Q14 } & 0.587 \\ & \text { Q15 } & 0.795 \\ & \text { Q16 } & 0.734\end{array}$

Note: Eigenvalue 18.03, 1.26, and 1.13, 69\% variance explained.

Table 6 displays the correlation results for each factor. The results ranged from .295 for discussion and feedback to .746 for teaching material and assessments, indicating that the level of correlation ranked between low and strong.

Table 6

Summary of Non-parametric Correlation Metrics using Spearman Rank Correlation

\begin{tabular}{|c|c|c|c|c|}
\hline & \multicolumn{2}{|c|}{ SML-Intrinsic Motivation } & \multicolumn{2}{|c|}{ SML-Extrinsic Motivation } \\
\hline & $\begin{array}{l}\text { Parametric } \\
\text { correlation (r) }\end{array}$ & $\begin{array}{l}\text { Non-Parametric } \\
\text { correlation (r) }\end{array}$ & $\begin{array}{l}\text { Parametric } \\
\text { correlation (r) }\end{array}$ & $\begin{array}{l}\text { Non-Parametric } \\
\text { correlation (r) }\end{array}$ \\
\hline $\begin{array}{l}\text { Teaching } \\
\text { materials and } \\
\text { assessments }\end{array}$ & $.746^{* * *}$ & $.678^{* *}$ & $.670 * *$ & $.586^{* * *}$ \\
\hline $\begin{array}{l}\text { Discussion and } \\
\text { feedback }\end{array}$ & $.343^{* *}$ & $.349^{* *}$ & $.299 * *$ & $.295^{* *}$ \\
\hline
\end{tabular}

** Indicates 0.01 level of significance (2-tailed).

The results of this research show that both key-aspects in Table 6 and motivation variables, both intrinsic and extrinsic, were significantly and positively correlated. However, the degree of correlation varied, being stronger in regard to e-teaching materials and e-assessments (Paechter \& Maier, 2010). In contrast to Zheng et al. (2018), this study found a weak correlation between motivation variables and e-discussion and e-grade checking and feedback.

\section{Discussion}

The main results show significant positive correlations between the key aspects of elearning and students' motivation to learn in AU. This is evidence of the importance of the appropriate use of key aspects of e-learning in relation to students' motivation to learn. AU students have experience dealing with Moodle activities related to e-teaching materials and eassessments. Since the inception of Moodle at AU, the majority of the Moodle activities used by the students are related to these two activities. Prior experience with Moodle may have also contributed to the high correlation between motivation and e-teaching materials and eassessments. This argument is supported by other researchers (Yili \& Tsai, 2017; Slater \& Davies, 2020; Cundell \& Sheepy, 2018). The low correlation between motivation variables and e-discussion and e-grade checking and feedback could be attributed to the absence of real-time 
interaction between students and faculty in the way e-discussion and e-grade checking and feedback are implemented.

The implications of these research findings indicate, on the one hand, that AU students were intrinsically motivated toward learning via e-teaching materials and e-assessments and, on the other, that they are aiming to get good grades (extrinsic motivation) without sufficient engagement in asynchronous activities. This implies that the university needs to encourage faculty to develop strategies to further engage students with such activities to comprehend the course concepts intrinsically and extrinsically (Mitchell, 2019; Buelow et al., 2018). In addition, AU should consider developing a course that can be taken early in the student's term of study and orients them to the importance of asynchronous activities.

\section{Conclusions}

Motivating students to learn is a very important factor, and one which can contribute to improving the quality of education. In this paper, associations between key aspects of e-learning and students' motivation to learn were researched via an administered questionnaire completed by a pool of students studying at AU. The research results show a significant positive correlation between key aspects of e-learning and students' motivation to learn in AU. More specifically, the results indicate that AU students were strongly motivated in e-teaching materials and eassessments but less so in regard to e-discussions and e-grade checking and feedback. The health crisis recently caused by the COVID-19 pandemic has increased the use of e-learning. As distance education continues to grow, more attention should be paid to how to integrate keyaspects of e-learning into motivation variables to assist AU students achieve their highest potential in a predominantly traditional system of higher education.

\section{Limitations and Future Research}

This research is limited in scope and did not include some factors such as key performance indicators and students' approaches to learning. Future research can attempt to address these limitations whilst sampling students across multiple universities in the UAE. 


\section{References}

Buelow, J. R., Barry, T., \& Rich, L. E. (2018). Supporting learning engagement with online students. Online Learning, 22(4), 313-340. https://doi:10.24059/olj.v22i4.1384

Chan, D. K. C., Yang, S. X., \& Hamamura, T. (2015). In-lecture learning motivation predicts students' motivation, intention, and behaviour for after-lecture learning: Examining the transcontextual model across universities from UK, China, and Pakistan. Motivation and Emotion, 39(6), 908-925. https://doi.org/10.1007/s11031-015-9506-X

Chan, K., Lai, S., Leung, H., \& Wan, K. (2016). Engagement in online asynchronous discussions: Roles of students' interests and preferences. Proceedings of the International Conference on e-Learning, ICEL, Jun 2016, 32-36.

Chang, M. M., \& Lehman, J. (2002). Learning foreign language through an interactive multimedia program: An experimental study on the effects of the relevance component of the ARCS model. CALICO Journal, 20(1), 81-98.

Cortina, J. M. (1993). What is coefficient alpha? An examination of theory and applications. Journal of Applied Psychology, 78(1), 98-104.

Cronbach, L. J. (1951). Coefficient alpha and the internal structure of tests. Psychometrika, 16, 297-334.

Cundell, A., \& Sheepy, E. (2018). Student perceptions of the most effective and engaging online learning activities in a blended graduate seminar. Online Learning, 22(3), 87-102. https://doi:10.24059/olj.v22i3.1467

Dennen, V. P., \& Bagdy, L. M. (2019). From proprietary textbook to custom OER solution: Using learner feedback to guide design and development. Online Learning, 23(3), 4-20. https://doi:10.24059/olj.v23i3.2068

Ellis, R. A., Ginns, P., \& Piggott, L. (2009). E-learning in higher education: Some key aspects and their relationship to approaches to study. Higher Education Research \& Development, 28, 303-318.

Guo, Y. R., Goh, D., \& Luyt, B. (2017). Tertiary students' acceptance of a game to teach information literacy. Aslib Journal of Information Management, 69(1) 46-

63. https://doi.org/10.1108/AJIM-08-2016-0131

Harandi, R. S. (2015). Effects of e-learning on students' motivation. Procedia - Social and Behavioral Sciences 181, 423-430.

Hirumi, A., Sivo, S., \& Pounds, K. (2012). Storytelling to enhance teaching and learning: the systematic design, development, and testing of two online courses. International Journal on ELearning, 11(2) 125-151. 
Hoban, J. D., Lawson, S. R., Mazmanian, P. E., Best, A.M., \& Seibel, H. R. (2005). The selfdirected learning readiness scale: A factor analysis study. Medical Education, 39(4), 370-379. https://doi.org/10.1111/j.1365-2929.2005.02140.x

Imansari, A., Umamah, N., \& Na'im, M. (2018). The usage of e-book as learning media through the sigil application in history. IOP Conf. Series: Earth and Environmental Science, 243, 012155. https://doi:10.1088/1755-1315/243/1/012155

Irawan, M. I., Mukhlash, I., Adzkiya, D., Darmadi, \& Sanusi. (2019). Development of trigonometric visualization concepts to increase the study motivations of SMK students. International Conference on Mathematics: Pure, Applied and Computation. Journal of Physics: Conf. Series 1218. https://doi:10.1088/1742-6596/1218/1/012049

Karagiannis, I., \& Satratzemi, M. (2018). Implementation of an adaptive mechanism in Moodle based on a hybrid dynamic user model. ICL 2018: The Challenges of the Digital Transformation in Education, 377-388.

Keller, J. M. (1987a). Strategies for stimulating the motivation to learn. Performance and Instruction, 26(8), 1-7.

Keller, J. M. (1987b). The systematic process of motivational design. Performance and Instruction, 26(9/10), 1-8.

Keller, J. M. (2008). An integrative theory of motivation, volition, and performance. Technology, Instruction, Cognition, and Learning, 6, 79-104.

Kim, C., Park, S. W., Huynh, N., \& Schuermann, R. T. (2017). University students' motivation, engagement and performance in a large lecture-format general education course. Journal of Further and Higher Education, 41(2), 201-214.

Kim, J. E., \& Lee, R. K. (2019). Effects of an examiner's positive and negative feedback on selfassessment of skill performance, emotional response, and self-efficacy in Korea: A quasiexperimental study. BMC Medical Education, 19(142). https://doi.org/10.1186/s12909-019$1595-\mathrm{x}$

Lim, S. C., \& Park, T. (2011). The declining association between earnings and returns: Diminishing value relevance of earnings or noisier markets? Management Research Review, 34(8), 947-960.

Maulana, W. A., Wilujeng, I., \& Kuswanto, H. (2019). Learning with the social media assisted science, technology and society approach to improve self-learning motivation. Journal of Physics: Conf. Series, 1233. https://doi:10.1088/1742-6596/1233/1/0120602

Mitchell, E. T. (2019). Using debate in an online asynchronous social policy course. Online Learning, 23(3), 21-33. https://doi:10.24059/olj.v23i3.2050 
Paechter, M., \& Maier, B. (2010). Online or face-to-face? Students' experiences and preferences in e-learning. The Internet and Higher Education 13, 292-297.

Palinkas, L. A., Horwitz, S. M., Green, C. A., Wisdom, J. P., Duan, N., \& Hoagwood, K. (2015). Purposeful sampling for qualitative data collection and analysis in mixed method implementation research. Adm Policy Ment Health 42, 533-544. https://doi.org/10.1007/s10488-013-0528-y

Prosser, M., Ramsden, P., Trigwell, K., \& Martin, E. (2003). Dissonance in experience of teaching and its relation to the quality of student learning. Studies in Higher Education, 28, 3748.

Pugh, C. (2019). Self-determination: Motivation profiles of bachelor's degree-seeking students at an online, for-profit university. Online Learning, 23(1), 111-131. doi:10.24059/olj.v23i1.1422

Rahrouh, M., Taleb, N., \& Mohamed, E. M. (2018). Evaluating the usefulness of e-learning management system delivery in higher education. Int. J. Economics and Business Research, $16(2), 162-181$.

Rice, W. (2015). Moodle e-learning course development (3rd ed.) Packt.

Sadaf, A., Martin, F., \& Ahlgrim-Delzell, L. (2019). Student perceptions of the impact of quality Matters-certified online courses on their learning and engagement. Online Learning, 23(4), 214233. https://doi:10.24059/olj.v23i4.2009

Slater, D. R., \& Davies, R. (2020). Student preferences for learning resources on a land-based postgraduate online degree program. Online Learning, 24(1), 140-161.

https://doi:10.24059/olj.v24i1.1976

Snow, R. (1990). Aptitude-treatment interaction as a framework for research on individual difference in learning. In P. Ackerman, R. Sternberg, \& R. Glaser (Eds.), Learning and individual differences (pp. 13-59). Freeman.

Songül, K., \& Hakan, P. (2019). The effects of the flipped classroom model designed according to the ARCS motivation strategies on the students' motivation and academic achievement levels. Education and Information Technologies 25, 1475-1495. https://doi:10.1007/s10639-019-09985$\underline{1}$

Stark, E. (2019). Examining the role of motivation and learning strategies in student success in online versus face-to-face courses. Online Learning, 23(3), 234-251.

https://doi:10.24059/olj.v23i3.1556

Tibi, M. H. (2018). Computer science students' attitudes towards the use of structured and unstructured discussion forums in online courses. Online Learning, 22(1), 93-106. https://doi:10.24059/olj.v22i1.995

Tokan, K. M., \& Imakulata, M. M. (2019). The effect of motivation and learning behaviour on student achievement. South African Journal of Education, 39(1). 
Truhlar, A. M., Williams, K. M., \& Walter, M. T. (2018). Case study: Student engagement with course content and peers in synchronous online discussions. Online Learning, 22(4), 289-312. https://doi:10.24059/olj.v22i4.1389

Tseng, H., \& Walsh, E. J. (2016). Blended versus traditional course delivery comparing students' motivation, learning outcomes, and preferences. Quarterly Review of Distance Education, 17(1), 43-52.

Vero, E., \& Puka, E. (2017). The importance of motivation in an educational environment. Formazione \& Insegnamento XV(1), 57-66. https://doi:107346/-fei-XV-01-17 05

Wan, Z., Wang Y., \& Haggerty N., (2008). Why people benefit from e-learning differently: The effects of psychological processes on e-learning outcomes. Information \& Management, 45(8), 513-521.

YiLi, L., \& Tsai, C. (2017). Accessing online learning material: Quantitative behavior patterns and their effects on motivation and learning performance Author links open overlay panel. Computers \& Education, 114, 286-297. https://doi.org/10.1016/j.compedu.2017.07.007

Zheng, C., Liang, J. C., Li, M., \& Tsai, C-C. (2018). The relationship between English language learners' motivation and online self-regulation: A structural equation modelling approach. System, 76, 144-157. 